\title{
Interdisciplinary Tasks in the Cyclotron Production of Radiometals for Medical Applications. The Case of ${ }^{47} \mathrm{Sc}$ as Example
}

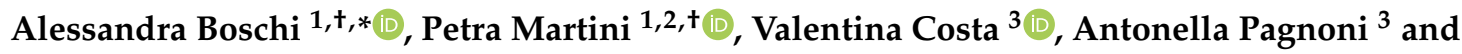 \\ Licia Uccelli ${ }^{1}$ \\ 1 Department of Morphology, Surgery and Experimental Medicine, University of Ferrara, Via Luigi Borsari, \\ 46-44121 Ferrara, Italy; petra.martini@unife.it (P.M.); licia.uccelli@unife.it (L.U.) \\ 2 Legnaro National Laboratories, Italian National Institute for Nuclear Physics (LNL-INFN), \\ Viale dell' Università, 2, 35020 Legnaro (PD), Italy \\ 3 Department of Chemical and Pharmaceutical Sciences, University of Ferrara, Via Luigi Borsari, \\ 46-44121 Ferrara, Italy; valentina.costa@unife.it (V.C.); antonella.pagnoni@unife.it (A.P.) \\ * Correspondence: alessandra.boschi@unife.it; Tel.: +39-0532-455-354 \\ + These authors contributed equally to this work.
}

Academic Editors: Carlo Santini and Maura Pellei

Received: 7 December 2018; Accepted: 24 January 2019; Published: 26 January 2019

\begin{abstract}
The growing number of cyclotrons of different sizes installed in the territory has given a strong impulse to the production of conventional and emerging radionuclides for medical applications. In particular, the great advantage of using medical cyclotrons is the possibility to produce on-site, when needed (on-demand), with medical radionuclides of interest encouraging the personalized medicine approach. Radiometals satisfy the ideal characteristics that radionuclides should have for routine employment in nuclear medicine, especially since they have a robust chemistry suitable to synthetize stable in vivo radiopharmaceuticals with high radiochemical yields. In this letter several interdisciplinary aspects involved in the radiometals cyclotron production cycle are summarized focusing the attention on cyclotron production facilities, target material, and chemical processing available for medical applications. As an example, the current status and recent development in the production of the theranostic radionuclide scandium- 47 have been reported.
\end{abstract}

Keywords: radiometals; cyclotron; target; automation; radiochemical separation

\section{Introduction}

Nuclear medicine (NM) is based on the use of radiopharmaceuticals, pharmaceutical drugs containing one or more radioactive nuclides, to investigate different kind of diseases such as heart disease, neurological, endocrine, gastrointestinal disorders and other anomalies within the body, metabolic processes, or to treat tumors. Moreover, NM is considered as a part of molecular imaging since, by using a wide range of different emitter radionuclides and radiopharmaceuticals, it provides pictures of what is happening inside the body at the molecular and cellular level with the aim to study specific biological process including pathophysiology of certain diseases [1-4]. There are two kinds of radionuclides involved in diagnostic procedures: those that directly decay by emitting $\gamma$ rays, suitable for conventional NM scans, such as single-photon emission computed tomography (SPECT), and those that decays by $\beta^{+}$emission which subsequently undergoes annihilation with an electron emitting two gamma rays at $511 \mathrm{keV}$ each, suitable for positron emission tomography (PET). In nuclear medicine, it is also possible to perform therapeutic treatments of tumors employing nuclides having high energy $\beta^{-}$or $\alpha$ emission able to destroy cells responsible for pathologies thanks to the biological effects of the emitted radiation $[1,5,6]$. A new frontier of nuclear medicine is in theranostics, 
a medical approach introduced by Herzog et al. [7,8] in 1993, combining therapeutic and diagnostic effects by using radionuclides with proper decay radiations (single-element theranostics radionuclides e.g., ${ }^{47}$ Sc: $\mathrm{T}_{1 / 2}=3.3492$ days, $\mathrm{E}_{\gamma}=159.381 \mathrm{keV}$ and $\mathrm{E}_{\beta \text {-mean }}=162.0 \mathrm{keV}$; multiple-element theranostics radiopharmaceuticals e.g. ${ }^{188} \operatorname{Re}: \mathrm{T}_{1 / 2}=17.004 \mathrm{~h}, \mathrm{E}_{\beta \text {-mean }}=763 \mathrm{keV}$ with ${ }^{99 \mathrm{~m}} \mathrm{Tc}_{\mathrm{c}}: \mathrm{T}_{1 / 2}=6.0072 \mathrm{~h}$, $\mathrm{E}_{\gamma}=140.511 \mathrm{keV}$ [9]). Theranostics provides a personalized medicine approach allowing the selection of patients that will benefit from the particular treatment, also avoiding unnecessary and expensive therapies [8,10-12].

The choice of the appropriate radionuclide is based not only on its nuclear and chemical properties but also on production easiness, costs, and prompt availability. In general, nuclides employed for diagnostic procedures should: (1) have a half-life long enough to allow the radiopharmaceutical preparation but short enough to minimize the adsorbed patient dose (in general less than $24 \mathrm{~h}$ ); (2) emit only low energy gamma radiations or $\beta^{+}$particles, suitable for SPECT or PET imaging respectively; (3) have a robust chemistry and chemical properties suitable to synthetize radiopharmaceuticals with high radiochemical yields and particularly stable in vivo. Unfortunately, there are no nuclides able to completely satisfy all those characteristics and, therefore, only few radionuclides are routinely employed in NM. Those that mostly show similar characteristics to those indicated above are metals. Thanks to their rich coordination chemistry, transition metals offer a wide range of opportunities to link with different ligands in radiopharmaceutical preparations.

Radiometals can be produced by different methods: nuclear reactors, generators, and cyclotrons, each of them having advantages and disadvantages. Nuclear reactor is a centralized production method characterized by high production efficiency, which guarantee the supply to a large territory, but presents as main disadvantages the high investment and operational costs and the production of large amount of long-lived radioactive waste, in addition to public safety issues.

The production of radionuclides by cyclotron offers several advantages, including high specific activity of the produced radionuclide, decentralized production easily programmable, smaller production of long-lived radioactive waste than in nuclear reactors, and smaller investment. In particular, the technological advancement in the cyclotron-based radionuclides production sector has given a strong impetus to the use of radiometals in medical applications [13-15].

The radionuclide generator systems intrinsically need an appropriate long-lived parent radionuclide, on which the short-lived daughter radionuclide production is based, and its in-house use depends on the timed elution cycles [14].

The scope of this letter is to provide a short overview on the different interdisciplinary and tightly connected aspects involved in the cyclotron production of radiometals for nuclear medicine. A particular section will be dedicated to the current status and recent development in the production of the theranostic radionuclide ${ }^{47} \mathrm{Sc}$.

\section{Cyclotron Production Facilities}

Among particle accelerators, cyclotron is the most frequent choice for radionuclides production [15]. Cyclotrons can accelerate different particles such as protons, deuterons, and alphas at variable energies originating nuclear reactions making possible the production of a wide variety of medical isotopes. Main advantages of using accelerators for the production of medical radionuclides lies in the high specific activity (SA) achievable, the smaller amount of radioactive waste generated compared to nuclear reactors, the cost-effectiveness and scalable on-demand daily availability of the radionuclides.

The growing number of cyclotrons of different sizes [16] installed on the territory is in line with the constant expansion of radionuclides needs for Nuclear Medicine applications. Small cyclotrons (proton energy, Ep $<20 \mathrm{MeV}$ ), whose number around the world in the last ten years has practically doubled, are the tool of choice for the in-hospital production of most PET isotopes routinely involved in diagnostic investigations [17]. They are located in regional centers for the production of short half-life PET radionuclides in sufficient amount to cover the hospital needs and many of them have a 
multiple targets capability on two or more extracted beamlines [18]. Medium cyclotrons, with energies between 20 to $35 \mathrm{MeV}$, are usually installed in academic research institutes or commercial facilities specialized in production of intermediate half-life SPECT and PET radionuclides. Large multi-purpose research cyclotrons, with energies greater than $35 \mathrm{MeV}$ and up to $500 \mathrm{MeV}$, are commonly located in academies and governments research institutes and are mostly used for the production of therapeutic radionuclides, parent nuclides to be loaded onto generator systems and for research [18].

A wide selection of radiometals can be produced by cyclotron. In particular, small medical cyclotrons, are currently producing, routinely or on research scale, ${ }^{99 \mathrm{~m}} \mathrm{Tc},{ }^{124} \mathrm{I},{ }^{89} \mathrm{Zr},{ }^{64} \mathrm{Cu},{ }^{67} \mathrm{Ga},{ }^{68} \mathrm{Ga}$, ${ }^{86} \mathrm{Y},{ }^{44} \mathrm{Sc}$, and ${ }^{111} \mathrm{In}$ [19]. Increasing the beam energy to 30-35 $\mathrm{MeV}$ nuclear reactions gives access to a large number of isotopes such as ${ }^{201} \mathrm{Tl},{ }^{67} \mathrm{Ga},{ }^{111} \mathrm{In}$ and ${ }^{64} \mathrm{Cu}$; while cyclotron that accelerate protons up to around $70 \mathrm{MeV}$ can also produce ${ }^{82} \mathrm{Sr},{ }^{68} \mathrm{Ge},{ }^{67} \mathrm{Cu}$, and ${ }^{47} \mathrm{Sc}$ [20]. In Table 1 a list of "cyclotron-produced" radiometals and some of possible nuclear reactions are reported.

Table 1. List of cyclotron-produced radiometals and some of possible nuclear reactions [9].

\begin{tabular}{cccc}
\hline radionuclide & Life-time & Nuclear Reaction & Application \\
\hline${ }^{61} \mathrm{Cu}$ & $3.33 \mathrm{~h}$ & ${ }^{64} \mathrm{Zn}(\mathrm{p}, \alpha)$ & PET \\
${ }^{64} \mathrm{Cu}$ & $12.7 \mathrm{~h}$ & ${ }^{64} \mathrm{Ni}(\mathrm{p}, \mathrm{n})$ & PET \\
${ }^{67} \mathrm{Cu}$ & $61.9 \mathrm{~h}$ & ${ }^{68} \mathrm{Zn}(\mathrm{p}, 2 \mathrm{p})$ & Therapy/SPECT \\
${ }^{67} \mathrm{Ga}$ & $78.3 \mathrm{~h}$ & ${ }^{68} \mathrm{Zn}(\mathrm{p}, 2 \mathrm{p})$ & SPECT \\
${ }^{68} \mathrm{Ga}$ & $68 \mathrm{~min}$ & ${ }^{69} \mathrm{Ga}(\mathrm{p}, 2 \mathrm{n})^{68} \mathrm{Ge} \rightarrow{ }^{68} \mathrm{Ga}$ & PET \\
${ }^{82 \mathrm{~m}} \mathrm{Rb}$ & $5 \mathrm{~min}$ & ${ }^{85} \mathrm{Rb}(\mathrm{p}, 4 \mathrm{n}){ }^{82} \mathrm{Sr} \rightarrow{ }^{82 \mathrm{~m}} \mathrm{Rb}$ & PET \\
${ }^{44} \mathrm{Sc}$ & $3.97 \mathrm{~h}$ & ${ }^{44} \mathrm{Ca}(\mathrm{p}, \mathrm{n})$ & PET \\
${ }^{47} \mathrm{Sc}$ & $77 \mathrm{Ti}(\mathrm{n}, \mathrm{p})$ & Therapy/SPECT \\
${ }^{99 \mathrm{~m}} \mathrm{Tc}$ & $79.2 \mathrm{~h}$ & ${ }^{48} \mathrm{Ca}(\mathrm{p}, 2 \mathrm{n})$ & SPECT \\
${ }^{86} \mathrm{Y}$ & $6 \mathrm{~h}$ & ${ }^{100} \mathrm{Mo}(\mathrm{p}, 2 \mathrm{n})$ & PET \\
${ }^{103} \mathrm{Pd}$ & 14.7 & ${ }^{86} \mathrm{Sr}(\mathrm{p}, \mathrm{n})$ & Therapy \\
${ }^{111} \mathrm{In}$ & $17.5 \mathrm{~d}$ & ${ }^{103} \mathrm{Rh}(\mathrm{p}, \mathrm{n})$ & SPECT \\
${ }^{186} \mathrm{Re}$ & $67.2 \mathrm{~h}$ & ${ }^{112} \mathrm{Cd}(\mathrm{p}, 2 \mathrm{n})$ & Therapy/SPECT \\
${ }^{201} \mathrm{Tl}$ & $90.6 \mathrm{~h}$ & ${ }^{886} \mathrm{~W}(\mathrm{p}, \mathrm{n})$ & SPECT \\
${ }^{89} \mathrm{Zr}$ & $73.5 \mathrm{~h}$ & ${ }^{203} \mathrm{Tl}(\mathrm{p}, 3 \mathrm{n}){ }^{201} \mathrm{~Pb} \rightarrow{ }^{201} \mathrm{Tl}$ & PET \\
\hline
\end{tabular}

\section{Radiometals Cyclotron-Production Process}

Several interdisciplinary tasks and expertise are necessary to accomplish the production route of radiometals by means of cyclotrons. The theoretical knowledge of the nuclear reaction cross-sections involved in the production, for example, is required in the choice of the optimal irradiation parameters, that usually lies in a compromise between production yield and quality parameters such as isotopic purity (IP) and radionuclidic purity (RNP). Competence in engineering, chemistry, and material sciences are fundamental in the choice of a dedicated target (either solid, liquid, or gas target), in the development of a highly efficient separation/purification procedure in order to achieve high radiochemical purity (RCP) and RNP products, and in the development of a target recovery process to minimize production costs. In Figure 1a a schematic representation of a radiometal cyclotron production cycle for medical application is reported. Moreover, the radiometal cyclotron production must be supported by quality controls to evaluate the injectability and quality of produced metal used then for the preparation of final radiopharmaceutical product. Figure $1 \mathrm{~b}$ pointed the diverse nature of involved competence and interrelated tasks and contributions.

In the following section the principal technological aspects of the radiometal cyclotron production cycle will be discussed. 


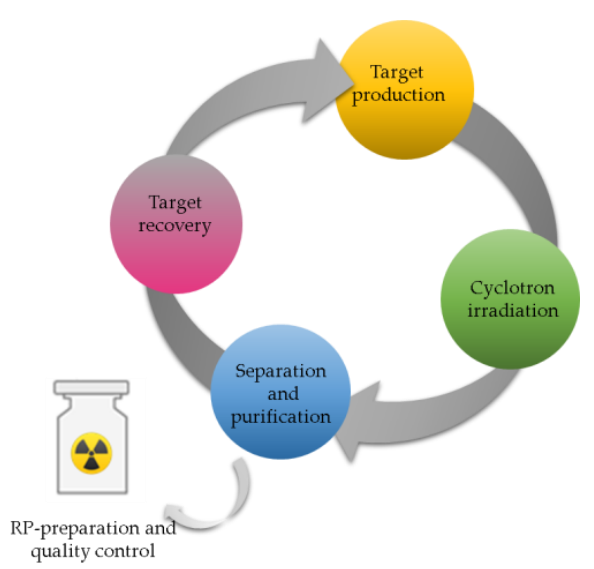

(a)

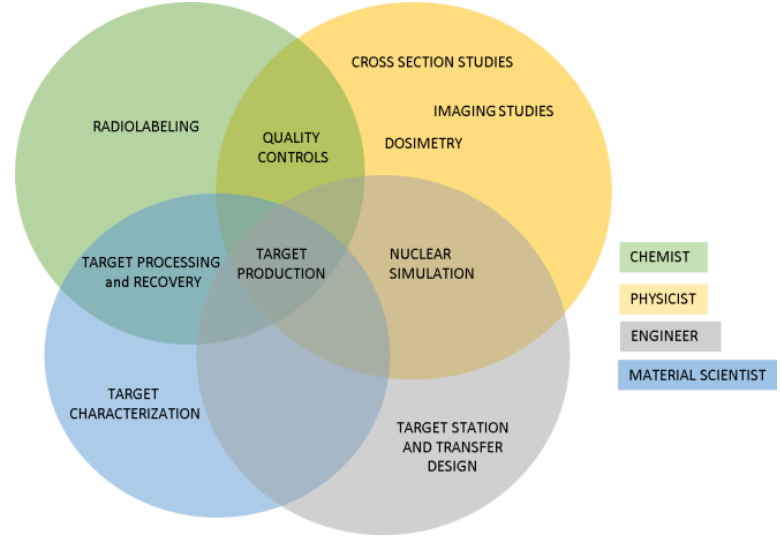

(b)

Figure 1. (a) Radiometal cyclotron production cycle; (b) Involved competence and interrelated tasks and contributions.

\subsection{Solid and Liquid Targets}

Mainly two different kind of targets can be used for radiometals cyclotron production: liquid and solid targets. There is no example of a gas target used for radiometals cyclotron production reported in the literature presently. Liquid targets have the advantage to be simple to handle and to produce, to allow a faster post-irradiation process, avoiding long dissolution procedure, and to be less expensive than solid configuration, since less material is involved. Contrariwise, solid targets, despite more expensive due to the high amount of enriched target material involved, allow higher production yields but requires more post-irradiation chemical separation steps (Figure 2). Moreover, hospital-based cyclotron facilities, solid targets require technological and structural investment for specific target station and more complex automated delivery systems. The cyclotron production of various positron-emitting radiometals, such as ${ }^{86} \mathrm{Y},{ }^{94 \mathrm{~m}} \mathrm{Tc},{ }^{89} \mathrm{Zr},{ }^{61} \mathrm{Cu},{ }^{68} \mathrm{Ga}$, and ${ }^{44 \mathrm{~g}} \mathrm{Sc}$, using a liquid target has been intensively investigated in the past ten years [21-30]. Several problems correlated with the use of liquid targets were reported. In particular, the corrosiveness of the metal acidic salt solutions, degrading the internal surface of target body and the HAVAR $®$ foil; the development of gas during the irradiation, determining an overpressure in the target; and salt precipitation $[21,22,30]$. To overcome these problems, the following solutions have been proposed:

$\rightarrow$ substitution of the aluminum target body with one made of niobium, more resistant to corrosion;

$\rightarrow$ usage of nitrate rather than chloride solution thus minimizing gas formation and avoiding HAVAR $^{\circledR}$ corrosion;

$\rightarrow$ addition of nitric acid to the target solution thus preventing the formation of solid precipitate and minimizing gas evolution;

$\rightarrow$ substitution of the HAVAR®foil with a niobium foil improving the resistance of the foil to the acidity of the target solution.

In the case of scandium-44, the use of liquid targets improved its availability for tracer development. This radiometal can be produced via ${ }^{44} \mathrm{Ca}(\mathrm{p}, \mathrm{n}){ }^{44 \mathrm{~g}} \mathrm{Sc}$ reaction by irradiating, with a $13 \mathrm{MeV}$ proton-beam cyclotron on a standard liquid target station, a liquid target solution containing a high concentration of natural-abundance calcium nitrate tetrahydrate $\left(\mathrm{Ca}\left(\mathrm{NO}_{3}\right)_{2} \cdot 4 \mathrm{H}_{2} \mathrm{O}\right)$ [24]. Alves et al. [28,29] have recently demonstrated that the production of ${ }^{68} \mathrm{Ga},{ }^{64} \mathrm{Cu}$, and ${ }^{61} \mathrm{Cu}$ through irradiation of liquid target allows to produce high specific activity of these radionuclides, reducing cost and processing time in comparison with cyclotron production through the solid target approach. The cyclotron production of ${ }^{68} \mathrm{Ga}$ is particularly interesting as it could economically strongly compete with the generator supply chain: $<25.000 €$ /year including the ${ }^{68} \mathrm{Zn}$ target recovery, a quarter of the 
generator-production costs [30]. Recently, Alves at al. [28] produced, with the liquid target technology, $6 \mathrm{GBq}$ of ${ }^{68} \mathrm{Ga}$ with a IBA $18 / 9$ Cyclone cyclotron. Moreover, Riga et al. (2018) have also demonstrated to be able to produce directly in hospital, $4 \mathrm{GBq}$ (at EOB) of ${ }^{68} \mathrm{Ga}$ with a GE PETtrace cyclotron [30].

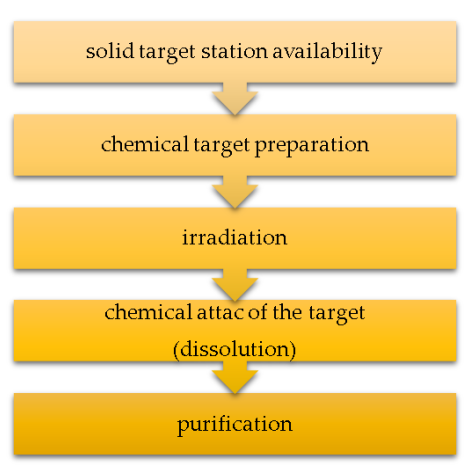

(a)

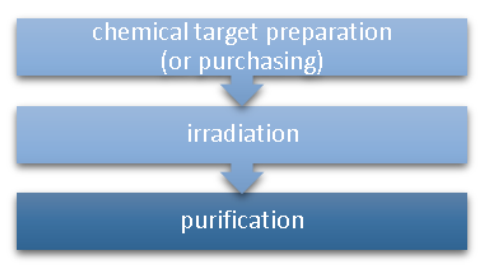

(b)

Figure 2. Radiometal cyclotron production approach through solid target (a) and liquid target (b).

Solid targets, in the form of metallic foil/coin, metallic powder or in oxide form, are mainly used for the cyclotron production of ${ }^{99 \mathrm{~m}} \mathrm{Tc},{ }^{67} \mathrm{Ga},{ }^{111} \mathrm{In},{ }^{64} \mathrm{Cu},{ }^{61} \mathrm{Cu},{ }^{68} \mathrm{Ge},{ }^{103} \mathrm{Pd}$, and ${ }^{89} \mathrm{Zr}$. For example, highly enriched ${ }^{100} \mathrm{Mo}$ targets are used for the direct cyclotron ${ }^{99 \mathrm{~m}} \mathrm{Tc}$ production, via the ${ }^{100} \mathrm{Mo}(\mathrm{p}, 2 \mathrm{p}){ }^{99 \mathrm{~m}} \mathrm{Tc}$ nuclear reaction while cadmium solid targets, highly enriched in the isotope 112, are commonly used for the cyclotron production of indium-111 via ${ }^{112} \mathrm{Cd}(\mathrm{p}, 2 \mathrm{n}){ }^{111} \mathrm{In}$ nuclear reaction $[31,32]$.

In Table 2 different type of target used for the cyclotron production of the selected radiometals are reported.

Table 2. Type of target used for the cyclotron production of the selected radiometals.

\begin{tabular}{|c|c|c|c|}
\hline Radionuclide & Target Type & Chemical form of the Target & References \\
\hline \multirow{2}{*}{${ }^{44} \mathrm{Sc}$} & solid & Metallic calcium pellets, ${ }^{44} \mathrm{CaCO}_{3}$ powder & {$[33,34]$} \\
\hline & liquid & ${ }^{44} \mathrm{Ca}\left(\mathrm{NO}_{3}\right)_{2} \times \cdot 4 \mathrm{H}_{2} \mathrm{O}$ solution & [24] \\
\hline \multirow{2}{*}{${ }^{64} \mathrm{Cu}$} & solid & ${ }^{64} \mathrm{Ni}(95 \%$ enrich.) & [35] \\
\hline & liquid & ${ }^{64} \mathrm{Ni}\left(\mathrm{NO}_{3}\right)_{2} \mathrm{x} \cdot 6 \mathrm{H}_{2} \mathrm{O}$ solution & [29] \\
\hline${ }^{67} \mathrm{Cu}$ & solid & ${ }^{\mathrm{s} 68} \mathrm{Zn},{ }^{\text {nat }} \mathrm{Zn},{ }^{70} \mathrm{Zn}$ metal; $\mathrm{ZnO}$ & {$[29,36]$} \\
\hline${ }^{67} \mathrm{Ga}$ & solid & ${ }^{68} \mathrm{Zn},{ }^{\text {nat }} \mathrm{Zn},{ }^{67} \mathrm{Zn}$ metal & [37] \\
\hline \multirow[b]{2}{*}{${ }^{68} \mathrm{Ga}$} & solid & ${ }^{68} \mathrm{Zn}$ metallic & {$[19,38]$} \\
\hline & liquid & ${ }^{68} \mathrm{Zn}\left(\mathrm{NO}_{3}\right)_{2} \times \cdot 6 \mathrm{H}_{2} \mathrm{O}$ solution & {$[21,28,30]$} \\
\hline${ }^{82} \mathrm{Sr}$ & solid & ${ }^{\text {nat }} \mathrm{RbCl}$ or nat $\mathrm{Rb}$ metal & [39] \\
\hline \multirow[b]{2}{*}{${ }^{86} \mathrm{Y}$} & solid & ${ }^{\text {nat }} \mathrm{SrCO}_{3}$ & [40] \\
\hline & liquid & ${ }^{\text {nat }} \mathrm{Sr}\left(\mathrm{NO}_{3}\right)_{2}$ solution & [21] \\
\hline \multirow[b]{2}{*}{${ }^{89} \mathrm{Zr}$} & solid & ${ }^{89} \mathrm{Y}$ foil, pellets, $\mathrm{Y}_{2} \mathrm{O}_{3}$ & [41] \\
\hline & liquid & ${ }^{\text {nat }} \mathrm{Y}\left(\mathrm{NO}_{3}\right)_{3} \cdot 6 \mathrm{H}_{2} \mathrm{O}$ solution & [21] \\
\hline${ }^{99 \mathrm{~m}} \mathrm{Tc}$ & solid & ${ }^{100}$ Mo metal & {$[13,42,43]$} \\
\hline${ }^{103} \mathrm{Pd}$ & solid & ${ }^{103} \mathrm{Rh}$ metal foil & {$[44,45]$} \\
\hline${ }^{111}$ In & solid & ${ }^{\text {nat }} \mathrm{Cd}$, enriched ${ }^{112} \mathrm{Cd}$ or ${ }^{\text {nat }} \mathrm{Ag}$ & [15] \\
\hline${ }^{186} \operatorname{Re}$ & solid & ${ }^{186} \mathrm{WO}_{3}$ & {$[46,47]$} \\
\hline${ }^{201} \mathrm{Tl}$ & solid & ${ }^{203} \mathrm{Tl}$ metal & [15] \\
\hline${ }^{203} \mathrm{~Pb}$ & solid & ${ }^{\text {nat }} \mathrm{Tl},{ }^{205} \mathrm{Tl}$ metal & [15] \\
\hline
\end{tabular}

\subsection{The role of Radiochemical Processing in the Radiometal Cyclotron-Production}

With the aim to obtain an injectable radiopharmaceuticals labelled with radiometals, the radiochemical processing of an irradiated target is a fundamental step in the cyclotron production. 
The process should also aim at recovering the enriched target material, that in general is very expensive. A radiochemical procedure should be fast, allow high recovery yield, high chemical, radiochemical and radionuclidic purity, high SA and sterility. To minimize human errors, ensure high process reproducibility and operators radiation protection the use of remotely controlled automatic systems is recommended $[13,29,46,48,49]$.

The choice of a radiochemical processing method, that can be applied for the extraction/separation and purification of a medical radiometal should take into account: (1) physical and chemical properties of the target material (e.g. liquid or solid); (2) physical and chemical properties of the desired radiometal produced in the target during the irradiation; (3) quality requirements of the final product for the human use (ruled by the Pharmacopoeia by means of specific monographs); and (4) quality requirements of the final product for specific radiolabeling process (ruled by pharmaceutical manufacturer in case of kit labeling procedure) [50].

In the case of solid targets, the radiochemical processing requires first a dissolution step of the target and, if necessary, further chemical treatments to convert the dissolved target into proper chemical species to be efficiently involved in the separation procedure [51]. In the case of liquid targets, the dissolution step is not necessary and only the chemical conversion to proper species may be requested. Further purification steps could be necessary using liquid targets since the dissolution of some materials coming from either the vacuum isolation foil or from the target body, resulting in the contamination with radioactive or stable metals salt, ions, etc., of the target solution may occur during the irradiation [51].

One or a combination of conventional separation methods such as chromatography, solvent extraction (SE), precipitation, distillation, etc., can be selected to isolate the desired radionuclides and eliminate radioactive contaminants.

Ion exchange chromatography is one of the most commonly used methods for radiometals separation in nuclear medicine radiopharmacies since it is readily adaptable to automation [15,49]. A pratical example is use for the purification of generator eluted gallium-68 for the preparation of ${ }^{68} \mathrm{Ga}-\mathrm{DOTA}-\mathrm{TOC}[49,52]$. Ion exchange chromatography is based on the distribution of an element between the mobile and solid phase depending on the ionic form, the solute concentration and the functional group on the resin. Anions are involved in the exchange when the functional groups of the solid phase are positively charged and, conversely, cations are involved when they are negatively charged. Effectiveness of the process can be modulated by variables such as ionic concentration, column volume and diameter, flow rate and eluents. This technique is very useful for separating radionuclides from the bulk target and is for example applied for the separation of copper isotopes from zinc and gallium contaminants (Figure 3).
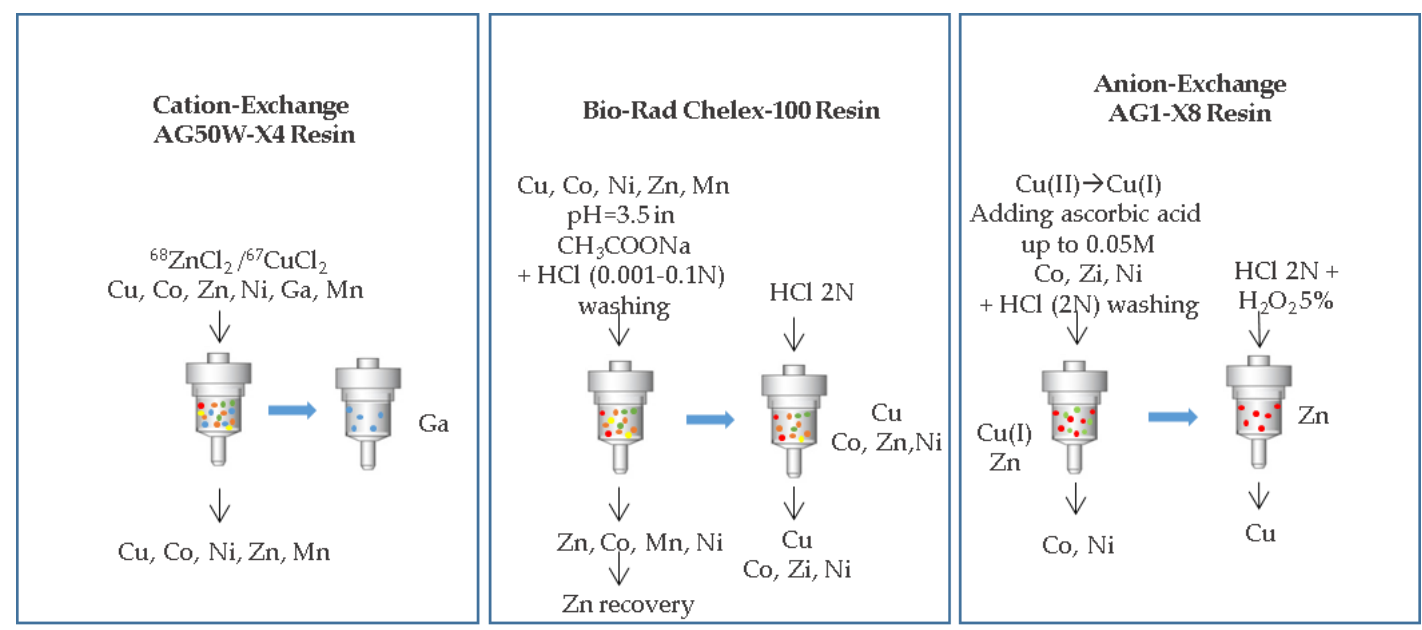

Figure 3. Schematic representation of the separation of copper isotopes from zinc and gallium contaminants reported by Medvedev et al. [53]. 
A particular type of chromatography, aqueous biphasic extraction chromatography (ABEC), was chosen for the separation of cyclotron produced ${ }^{99 \mathrm{~m}} \mathrm{Tc}$ as described by Schaffer et al. [43]. This method is based on the use of a hydrophobic polyethylene glycol (PEG)-based column resins, that immobilizes the ${ }^{99 \mathrm{~m}}$ Tc-pertechnetate leaving the molybdate flowing through.

The solvent extraction (SE) is a different separation method that can be efficiently applied for the separation of radiometals. For example SE allows the efficient separation of cyclotron produced ${ }^{99 \mathrm{~m}} \mathrm{Tc}$ after irradiation of metallic molybdenum metal target enriched in the isotope molybdenum-100 [54]. This method is based on the selective extraction by methyl ethyl ketone of ${ }^{99 \mathrm{~m}} \mathrm{Tc}$, in the chemical form of $\left[{ }^{99 \mathrm{~m}} \mathrm{Tc}\right] \mathrm{TcO}_{4}{ }^{-}$, from an alkaline solution containing pertechnetate, molybdate, and by products, in high yield and high quality. The SE of metals by an organic solvent, such as in the case of ${ }^{99 \mathrm{~m}} \mathrm{Tc}$, is often followed by further purification step of the product from the solvent, by means of column chromatography [55-58]. This method allows to obtain [ $\left.{ }^{99 \mathrm{~m}} \mathrm{Tc}\right] \mathrm{TcO}_{4}{ }^{-}$with high chemical and radiochemical purity suitable for the following radiolabeling procedure, particularly sensitive to the quality of ${ }^{99 \mathrm{~m}}$ Tc-pertechnetate solution $[13,59,60]$.

\section{Automation}

The entire automation of a radiochemical separation or a radiopharmaceutical synthesis is required for clinical application where the amount of radioactivity is high [61]. Commercial or custom-made modules are routinely involved in radiopharmacy practice for the preparation of small-scale radiopharmaceuticals (synthesis, dilution, purification, filtration, dispensing, etc.) [62]. Sector companies provide different customizable modules design suitable for the processing of radioactive materials together with a wide selection of consumables to personalize your own automatic procedure [52,55,62].

The module assembly consists in a mechanical and a chemistry part [62]. The building block of the module and other physical devices provided by the manufacturer, representing the mechanical part, usually are: (1) valves block: valves can be of different type (solenoid, pinch, pneumatic, rotary valves) and they can be two or three way valves made of different materials; (2) pumps: syringe, peristaltic and vacuum pump are the most used in this field; (3) gas flow controller or/and pressure regulator: as alternative way to perform liquid transfer; (4) reactor heater and fast cooling feature; and (5) detection instrumentation: pressure, UV, radiation detectors. The chemistry part, instead, is an assembly of vials, tubing, fittings, etc., in which reagent motion allows for a sequence of chemical operations and reactions to obtain the desired final product. This part can be pre-assembled by the manufacturer and provided as disposable device, called a cassette, or be non-disposable in permanent contact with the mechanical part. Mechanical and chemistry parts are connected and commanded by PLC (programmable logic controller), PC and graphical editing software for programming the sequence of the procedure together with a scheme of the fluid path as user interface.

The automation process of a separation and purification procedure is the final step of the process optimization.

Analytical characterization techniques, such as ICP-MS, ICP-OES, MP-AES, gas chromatography, etc., allow for the identification of the proper procedure, usually a combination of separation techniques aiming at separating and purifying the desired radionuclide from the target, other contaminants and solvents. Subsequently, a semi-automatic module can be designed as intermediate step useful when performing low activity experiments to optimize and define a continuity of the operations. Finally, the complete automation allows for: the reproducibility of the results, the minimization of activity losses and operation time, the maximization of the final recovery yield, the production under GMP rules.

\subsection{The Target Recovery}

The target recovery and its recycling is a very important step to complete the radiometal production cycle and make it economically sustainable. In most cases the production of radiometals by cyclotron require the use of highly enriched target material to achieve high radionuclidic and isotopic 
purity of the product. This is the case of ${ }^{64} \mathrm{Ni}$, used for the production of ${ }^{64} \mathrm{Cu}$, or ${ }^{100} \mathrm{Mo}$ used for the ${ }^{99 \mathrm{~m}} \mathrm{Tc}$ production by cyclotron, where the recovery and recycling of the target is very important to minimize the production costs. On the contrary there are cases for which recovery is not necessary, as for ${ }^{\text {nat }} \mathrm{Zn}$ target that is quite inexpensive [29].

A deep evaluation of the metal target recovery strategy needs to be done in order to keep the radiometal production costs within affordable limits and the quality parameters of the final product, from recycled target, within the pharmacopoeia limits. The chemical strategy to choose for the recovery is strictly dependent on the chemical form of the target material and the method used for the target production.

The most complex case in literature is represented by the metallic molybdenum-100 recovery after separation and purification of the direct cyclotron produced ${ }^{99 \mathrm{~m}} \mathrm{Tc}$. The molybdenum recovery in the metallic form needs several steps to first decompose the molybdate anions into trioxide $\mathrm{MoO}_{3}$ form, then to reduce the oxide in the metallic form by a multi-step hydrogen reduction. Gagnon, et al. [63] used a two-step reduction procedure: an exothermic conversion of $\mathrm{MoO}_{3}$ to $\mathrm{MoO}_{2}$ with a ramp rate between 500 and $750{ }^{\circ} \mathrm{C}$ in low concentration $\mathrm{H}_{2}$ gas atmosphere as a first step, while the second step consists in the reduction of $\mathrm{MoO}_{2}$ to Mo metal up to $1100{ }^{\circ} \mathrm{C}$ in $\mathrm{H}_{2} 100 \%$ atmosphere. To evaluate the reduction efficiency and the isotopic composition, $\mathrm{XRD}$ (X-ray diffraction) and inductively coupled plasma mass spectrometry (ICP-MS) characterization techniques need to be applied to the recycled sample. Gagnon et al. [63] reported a complete recovery cycle achieving an overall metal to metal yield of $87 \%$.

On the contrary, the recovery of metals that can be conveniently treated for electroplating results more simple to perform. Electrolytic cells can be integrated in the automated unit used for the delivery/recovery of the metal by pneumatic systems. Matarrese et al. [64] reported a procedure for dynamic Ni electroplating with recirculation of the electrolytic solution in a well-defined volume of a cylindrical chamber, integrated in an automated module for $\mathrm{Cu}$ radioisotope production.

\section{The case of Cyclotron Produced ${ }^{47}$ Sc: an Example}

Scandium-47 $\left(\mathrm{T}_{1 / 2}=3.35 \mathrm{~d}\right)$ is particularly interesting for radio immunotherapy of small tumors and cancer metastases due to its suitable $\beta^{-}$emission $\left(\mathrm{E}_{\beta \mathrm{av}}=162.0 \mathrm{keV}\right)$. Together with ${ }^{44} \mathrm{Sc}$ (or ${ }^{43} \mathrm{Sc}$, it represents the ideal matched pair for theranostic applications [65]. Moreover, by exploiting its $\gamma$-emission at $159 \mathrm{keV}(68.3 \%)$, this radionuclide can be used as single theranostic radionuclide performing SPECT imaging studies. From the chemical point of view Sc(III) presents similar coordination chemistry to $\mathrm{Lu}(\mathrm{III})$ and $\mathrm{Y}(\mathrm{III})$, allowing the use of ligands already developed for two well-established radionuclides, ${ }^{177} \mathrm{Lu}\left(\mathrm{T}_{1 / 2}=6.647 \mathrm{~d}, \mathrm{E}_{\beta \mathrm{av}}=134.2 \mathrm{keV}\right)$ and ${ }^{90} \mathrm{Y}\left(\mathrm{T}_{1 / 2}=64.0 \mathrm{~h}\right.$, $\left.\mathrm{E}_{\beta \mathrm{av}}=933.6 \mathrm{keV}\right)[9,66,67]$.

The critical issue in the use of ${ }^{47} \mathrm{Sc}$ is the lack of availability in sufficient amount and at reasonable cost. Different routes have been explored in the past for the ${ }^{47} \mathrm{Sc}$ production (Table 3). These are mainly based on the use of nuclear reactor and neutrons irradiation $\left(E_{\mathrm{n}}>1 \mathrm{MeV}\right)$ of ${ }^{47} \mathrm{TiO}_{2}$ target via the ${ }^{47} \mathrm{Ti}(\mathrm{n}, \mathrm{p})^{47} \mathrm{Sc}$ reaction, or thermal neutron irradiation of target enriched in the isotope ${ }^{46} \mathrm{Ca}$ via the ${ }^{46} \mathrm{Ca}(\mathrm{n}, \gamma){ }^{47} \mathrm{Ca}\left(\mathrm{T}_{1 / 2}=4.5 \mathrm{~d}, \beta^{-}\right) \rightarrow{ }^{47} \mathrm{Sc}$ nuclear reaction [66]. This latter method presents the advantage of using a ${ }^{47} \mathrm{Ca} /{ }^{47} \mathrm{Sc}$ generator, but the disadvantage of the highly cost ${ }^{46} \mathrm{Ca}$ target material. Alternative production ways are based on proton or gamma irradiation of ${ }^{\text {nat }} \mathrm{Ti}$ or ${ }^{48} \mathrm{Ti}$ in electron linear accelerator with a lower efficiency in comparison with the nuclear reactor production. A new production way based on cyclotron has been recently proposed. Minegishi et al. [67] reported the cyclotron production of ${ }^{47} \mathrm{Sc}$ based on the alfa-irradiation of enriched ${ }^{44} \mathrm{Ca}$ target. Sadly, the low cross-section of the ${ }^{46} \mathrm{Ca}(\alpha, \mathrm{p})^{47} \mathrm{Sc}$ reaction does not allow to produce high amount of the desired radiometal necessary to perform clinical applications. 
Table 3. Direct and indirect ${ }^{47} \mathrm{Sc}$ production routes.

\begin{tabular}{cc}
\hline Direct Production & Indirect Production \\
\hline$\left.{ }^{48} \mathrm{Ca}(\mathrm{p}, 2 \mathrm{n})\right)^{47} \mathrm{Sc}$ & ${ }^{48} \mathrm{Ca}(\mathrm{p}, \mathrm{x})^{47} \mathrm{Ca} \rightarrow{ }^{47} \mathrm{Sc}$ \\
${ }^{46} \mathrm{Ca}(\alpha, \mathrm{p})^{47} \mathrm{Sc}$ & ${ }^{46} \mathrm{Ca}(\mathrm{n}, \gamma)^{47} \mathrm{Ca} \rightarrow{ }^{47} \mathrm{Sc}$ \\
${ }^{47} \mathrm{Ti}(\mathrm{n}, \mathrm{p})^{47} \mathrm{Sc}$ & \\
${ }^{48} \mathrm{Ti}(\mathrm{p}, 2 \mathrm{p}){ }^{47} \mathrm{Sc}$ & \\
${ }^{49} \mathrm{Ti}(\mathrm{p}, \mathrm{x})^{47} \mathrm{Sc}$ & ${ }^{49} \mathrm{Ti}(\mathrm{p}, 3 \mathrm{p})^{47} \mathrm{Ca} \rightarrow{ }^{47} \mathrm{Sc}$ \\
${ }^{50} \mathrm{Ti}(\mathrm{p}, \mathrm{x})^{47} \mathrm{Sc}$ & ${ }^{50} \mathrm{Ti}(\mathrm{p}, \mathrm{x})^{47} \mathrm{Ca} \rightarrow{ }^{47} \mathrm{Sc}$ \\
${ }^{n a t} \mathrm{~V}(\mathrm{p}, \mathrm{x})^{47} \mathrm{Sc}$ & \\
\hline
\end{tabular}

Khandaker et al. [68], reported a dataset for the ${ }^{\text {nat }} \mathrm{Ti}(\mathrm{p}, \mathrm{x}){ }^{43,44 \mathrm{~m}, 44 \mathrm{~g}, 46,47,48} \mathrm{Sc}$ production leading to various practical applications. In this study they demonstrated that optimum production, $12 \mathrm{MBq} / \mathrm{mA} \mathrm{h}$, of ${ }^{47} \mathrm{Sc}$ can be achieved by irradiating natural titanium target over the energy range $33-22 \mathrm{MeV}$ with only ${ }^{46,48} \mathrm{Sc}$ impurity of about $3 \%$. Moreover, using lower energy (<33 MeV) cyclotron and enriched ${ }^{50} \mathrm{Ti}$ target, the ${ }^{47} \mathrm{Sc}$ production in large amount minimizing the co-production of ${ }^{46,48} \mathrm{Sc}$ radionuclides could be possible.

From these considerations it is obvious that, the work of the physicist dedicated to study the most promising nuclear reactions, by measuring unknown cross sections, optimizing the irradiation parameters considering the co-production of contaminant radionuclides, became very helpful to respond to the increasing request of ${ }^{47} \mathrm{Sc}$ production for clinical applications. In fact, while non-isotopic impurities in irradiated target can be removed by optimized chemical separation processes, isotopic impurities (e.g., ${ }^{x z} \mathrm{Sc}$ ) can be minimized only using enriched isotopes as target materials and/or by carefully selecting the effective particle energy range in the target.

After the ${ }^{47} \mathrm{Sc}$ cyclotron production, the desired product has to be separated and purified from the target. In this field, skills in radiochemistry and analytical process are needed to design and optimize a radiochemical method to isolate ${ }^{47} \mathrm{Sc}$ in a chemical form suitable for radiolabeling. Variety of ${ }^{47} \mathrm{Sc}$ separation methods from metallic $\mathrm{Ti}, \mathrm{TiO}_{2}$, and $\mathrm{CaCO}_{3}$ targets based on solvent extraction by tri-n-butyl phosphate (TBP), extraction chromatography or ion exchange processes has been reported [66,68-70].

In the case of calcium targets, all proposed method are simple, fast and allow to recover high percentage of the desired radionuclide and to apply simple chemical procedure for recovery [20]. In the case of titanium targets, the proposed procedure are longer and sometimes requiring time consuming dissolution and evaporation steps because of the greatest difficult in dissolving the titanium in particular in the $\mathrm{TiO}_{2}$ form. Moreover, in the greatest part of the proposed procedures, the use of fluoridric acid is required and accordingly the employment of proper and resistant material to this acid is necessary [71].

Recently some procedures have been developed to dissolve titanium in metallic form using hot $\mathrm{HCl}$ solution $(8 \mathrm{M})$, avoiding the use of fluoridric acid, and separate ${ }^{43} \mathrm{Sc}$ from ${ }^{46} \mathrm{Ti}$ using a DGA extraction chromatographic resin [70]. This resin selectively retains Sc, leaving Ti to flow through the resin, in a $4 \mathrm{M} \mathrm{HCl}$ solution. Pourmant et al. [72] also reported the strong Sc(III) retention on DGA resin and the negligible $\mathrm{Ti}(\mathrm{III})$ retention at $\mathrm{HCl}$ molarities below $6 \mathrm{M}$. After elution with $4.0 \mathrm{~mL}$ of $\mathrm{HCl} 0.1 \mathrm{M}$ scandium is concentrated in a smaller volume by the use of a second column containing SCX cation exchange resin and eluted with $4.8 \mathrm{M} \mathrm{NaCl} / 0.13 \mathrm{M} \mathrm{HCl}$ as eluent.

Our group [73] also recently investigated a similar procedure (to be published) that allow to obtain scandium in a water solution using two DGA resins (Figure 4). Shortly, we dissolved $10 \mathrm{mg}$ of metallic ${ }^{\text {nat }} \mathrm{Ti}$ in $3 \mathrm{~mL}$ of boiling $4.0 \mathrm{M} \mathrm{HCl}$ and to the resulting solution $2 \mu \mathrm{L}(\sim 2 \mu \mathrm{g})$ of a standard solution of scandium in $\mathrm{HNO}_{3}$ have been added. The solution was loaded onto a $1 \mathrm{~mL}$ column cartridge, containing $\sim 87 \mathrm{mg}$ DGA-N extraction chromatographic resin (normal, particle size 50-100 $\mu \mathrm{m}$, TrisKem International, Bruz, France). After resin washing with $5 \mathrm{~mL}$ of $4.0 \mathrm{M} \mathrm{HCl}$ to ensure complete removal of Ti(III), Sc(III) was eluted in $4 \mathrm{~mL}$ of $0.1 \mathrm{M} \mathrm{HCl}$. The eluted scandium solution was rinsed with $1.5 \mathrm{~mL}$ of concentrate $\mathrm{HCl}$ to get a $\mathrm{HCl}$ solution at molarity around 2.5-3. The solution was loaded 
onto a second $1 \mathrm{~mL}$ column cartridge, containing $30 \mathrm{mg}$ DGA-N and after washing with $5.0 \mathrm{~mL}$ of $2.5 \mathrm{M} \mathrm{HCl}, \mathrm{Sc}(\mathrm{III})$ was eluted with $0.7 \mathrm{~mL}$ of water. The use of the second resin allows to maximize the scandium/titanium separation yield and concentrate the final product in a solution compatible with radiolabeling procedures. All eluted fractions were analyzed by ICP-OES and no trace (Ti detection limit $0.2 \mathrm{ppm}$ ) of titanium in the final scandium solution (recovery yield $>95 \%$ ) was found. This separation and purification procedure can be easily automated aiming to maximize the scandium isolation and recovery yield.

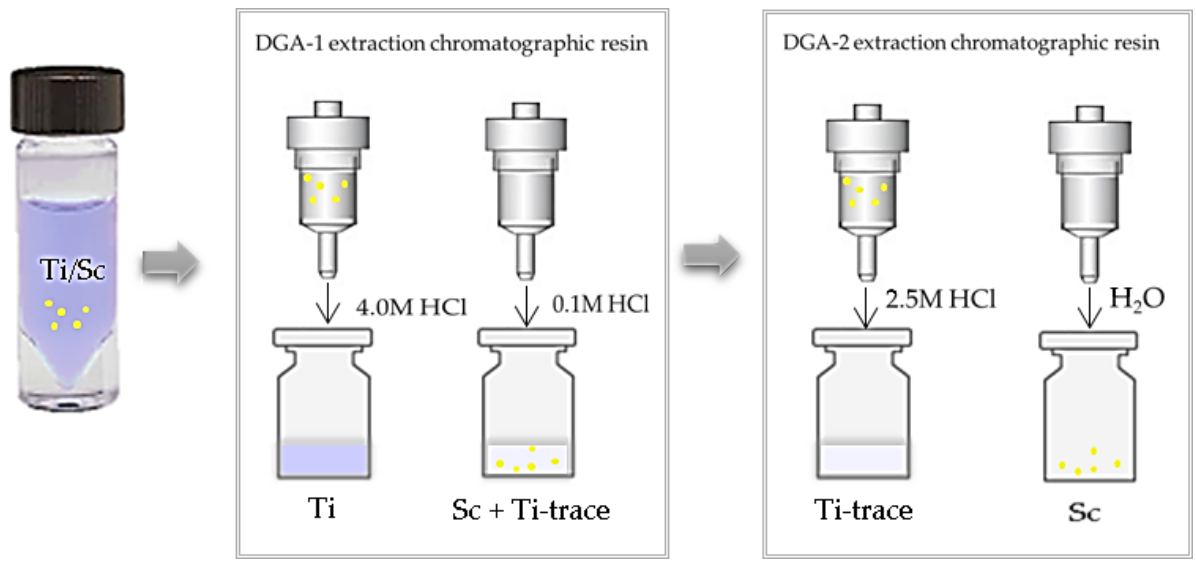

Figure 4. Schematic representation of the separation of scandium is from titanium using DGA-extraction chromatographic resin.

With the aim to reduce the production costs, due particularly to the elevated prizes of the highly enriched material used for the target, the recovery of calcium and titanium is also an important part in the ${ }^{47} \mathrm{Sc}$ cyclotron production process. Titanium recycling is generally performed at basic $\mathrm{pH}(\sim 8)$, that can be reached with ammonia solution, following the precipitation of $\mathrm{TiO}_{2}$ [67], while the recovery of calcium target can be performed though the precipitation of Ca-oxalate at $\mathrm{pH}$ of $4.5-5$ with subsequent conversion to carbonate by slowly heating up to $500{ }^{\circ} \mathrm{C}[74]$.

\section{Conclusions}

An overview on the different tasks involved in the radiometals production by cyclotron has been reported. It is clear form the above discussion is clear that different disciplines, knowledge, and competences are necessary: nuclear physics, that with nuclear reaction excitation function studies give a crucial input to choose an optimum target irradiation conditions in order to maximize desired isotope production and minimize unwanted by-products; mechanical engineering and material sciences are needed to address issues of target heating, induced mechanical stress, and material compatibility of targetry; radiochemists are involved in particular in the targeting post-processing to separate and purify the desired final cyclotron-produced radionuclide from the bulk target and impurities. All are also involved in the recovery of the target material, fundamental point to make the economically sustainable production.

With the aim to reduce the production costs and to encourage the research on the investigation of different radiometals radiopharmaceuticals, some studies are actually ongoing on the development of production strategies based on the use of liquid target as for ${ }^{86} \mathrm{Y},{ }^{89} \mathrm{Zr},{ }^{61} \mathrm{Cu}$, ${ }^{68} \mathrm{Ga}$, and ${ }^{44} \mathrm{Sc}$. This strategy avoids the use of a specific target station for solid targets and the dissolution of irradiated material, reducing the time of post-processing procedures. Unfortunately, this approach can not be used for the main part of radiometals and needs more studies dedicated to increase the production yields. At the same time, high-performance solid target design optimization, aiming at maximizing the heat dissipation efficiency, is the main goal of most research groups in this field. 
Author Contributions: Conceptualization: A.B., P.M.; writing-original draft preparation: A.B.; P.M.; writing-review and editing: A.B.; P.M.; experimental: A.B; P.M.; A.P.; V.C.; supervision: L.U.

Acknowledgments: The preliminary experimental results described in this manuscript are part of the research project PASTA founded by CSN5, Legnaro National Laboratories of Italian National Institute for Nuclear Physics (LNL-INFN). In this regard we would like to thank the PI Gaia Pupillo, Liliana Mou, and collaborators. We also thank FIR 2017 project of the University of Ferrara.

Conflicts of Interest: The authors declare no conflict of interest and declare that have not received funding, contracts or other forms of personal or institutional funding, with companies whose products are mentioned in the text.

\section{References}

1. Qaim, S.M. Nuclear data for medical applications: An overview. Radiochim. Acta 2001, 89, 189-196. [CrossRef]

2. Rodi, D.; Buzzi, A.; Barbieri, M.; Zucchini, S.; Verlengia, G.; Binaschi, A.; Regoli, D.; Boschi, A.; Ongali, B.; Couture, R.; et al. Bradykinin B2 receptors increase hippocampal excitability and susceptibility to seizures in mice. Neuroscience 2013, 27, 392-402. [CrossRef] [PubMed]

3. Pysz, M.A.; Gambhir, S.S.; Willmann, J.K. Molecular Imaging: Current Status and Emerging Strategies. Clin. Radiol. 2010, 65, 500-516. [CrossRef] [PubMed]

4. Mankoff, D.A. A definition of molecular imaging. Newsline J. Nucl. Med. 2007, 48, 18N-21N. Available online: http:/ /jnm.snmjournals.org/content/48/6/18N.long (accessed on 8 January 2019).

5. Boschi, A.; Martini, P.; Uccelli, L. ${ }^{188} \operatorname{Re}(\mathrm{V})$ nitrido radiopharmaceuticals for radionuclide therapy. Pharmaceuticals 2017, 10, 12. [CrossRef] [PubMed]

6. Uccelli, L.; Martini, P.; Pasquali, M.; Boschi, A. Monoclonal antibodies radiolabeling with rhenium-188 for radioimmunotherapy (RIT). BioMed Res. Int. 2017, 5923609. [CrossRef]

7. Herzog, H.; Rösch, F.; Stöcklin, L.C.; Qaim, S.M.; Feinendegen, L.E. Measurement of Pharmacokinetics of Yttrium-86 Radiopharmaceuticals with PET and Radiation Dose Calculation of Analogous Yttrium-90 Radiotherapeutics. J. Nucl. Med. 1993, 34, 2222-2226. [PubMed]

8. Yordanova, A.; Eppard, E.; Kürpig, S.; Bundschuh, R.A.; Schönberger, S.; Gonzalez-Carmona, M.; Feldmann, G.; Ahmadzadehfar, H.; Essler, M. Theranostics in nuclear medicine practice. Onco. Targets Ther. 2017, 10, 4821-4828. [CrossRef]

9. National Nuclear Data Center (NNDC) Database 2.6. Available online: http://www.nndc.bnl.gov/nudat2/ (accessed on 21 November 2018).

10. Smilkov, K.; Janevik, E.; Guerrini, R.; Pasquali, M.; Boschi, A.; Uccelli, L.; Di Domenico, G.; Duatti, A. Preparation and first biological evaluation of novel Re-188/Tc-99m peptide conjugates with substance-P. Appl. Radiat. Isot. 2014, 92, 25-31. [CrossRef]

11. Sivrastava, S.C. A Bridge not too Far: Personalized Medicine with the use of Theragnostic Radiopharmaceuticals. J. Postgrad. Med. 2013, 7, 31-46. [CrossRef]

12. Kelkar, S.S.; Reineke, T.M. Theranostics: Combining Imaging and Therapy. Bioconj. Chem. 2011, 22, $1879-1903$. [CrossRef] [PubMed]

13. Martini, P.; Boschi, A.; Cicoria, G.; Zagni, F.; Corazza, A.; Uccelli, L.; Pasquali, M.; Pupillo, G.; Marengo, M.; Loriggiola, M.; et al. In-house cyclotron production of high-purity Tc-99m and Tc-99m radiopharmaceuticals. Appl. Radiat. Isot. 2018, 139, 325-331. [CrossRef] [PubMed]

14. Qaim, S.M. The present and future of medical radionuclide production. Radiochim. Acta 2012, 100, 635-651. [CrossRef]

15. IAEA. Cyclotron Produced Radionuclides: Physical Characteristics and Production Methods; IAEA Technical Report No. 468; International Atomic Energy Agency: Austria, Vienna, 2009; ISBN 978-92-0-106908-5.

16. Cyclotrons Used for Radionuclide Production. Database of Cyclotrons for Radionuclide Production. Available online: https:/ / nucleus.iaea.org/sites/accelerators/Pages/Cyclotron.aspx (accessed on 8 January 2019).

17. Milton, B.F. Commercial Compact Cyclotrons in the 90's. In Proceedings of the 14th International Conference on Cyclotrons and their Applications, Cape Town, South Africa, 8-13 October 1996.

18. Schmor, P.W. Review of cyclotrons used in the production of radioisotopes for biomedical applications. In Proceedings of the CYCLOTRONS, Lanzhou, China, 6-10 September 2010; pp. 419-424.

19. Synowiecki, M.A.; Perk, L.R.; Nijsen, J.F.W. Production of novel diagnostic radionuclides in small medical cyclotrons. EJNMMI Radiopharm. Chem. 2018, 3, 3. [CrossRef] [PubMed] 
20. Misiak, R.; Walczak, R.; Was, B.; Bartyzel, M.; Mietelski, J.W.; Bilewicz, A. ${ }^{47}$ Sc Production development by cyclotron irradiation of ${ }^{48}$ Ca. J. Radioanal. Nucl. Chem. 2017, 313, 429-434. [CrossRef] [PubMed]

21. Oehlke, E.; Hoehr, C.; Hou, X.; Hanemaayer, V.; Zeisler, S.; Adam, M.J.; Ruth, T.J.; Celler, A.; Buckley, K.; Benard, F.; et al. Production of Y-86 and other radiometals for research purposes using a solution target system. Nucl. Med. Biol. 2015, 2, 842-849. [CrossRef] [PubMed]

22. Pandey, M.K.; Engelbrecht, H.P.; Byrne, J.P.; Packard, A.B.; DeGrado, T.R. Production of ${ }^{89} \mathrm{Zr}$ via the ${ }^{89} \mathrm{Y}(\mathrm{p}, \mathrm{n}){ }^{89} \mathrm{Zr}$ reaction in aqueous solution: Effect of solution composition on in-target chemistry. Nucl. Med. Biol. 2014, 41, 309-316. [CrossRef] [PubMed]

23. Degrado, T.R.; Byrne, J.P.; Packard, A.B.; Belanger, A.P.; Rangarajan, S.; Pandey, M.K. A solution target approach for cyclotron production of ${ }^{89} \mathrm{Zr}$ : Understanding and coping in-target electrolysis. J. Label. Compd. 2011, 54, S248.

24. Hoehr, C.; Oehlke, E.; Benard, F.; Lee, C.; Hou, X.; Badesso, B.; Ferguson, S.; Miao, Q.; Yang, H.; Buckley, K.; et al. ${ }^{44 \mathrm{~g} S c}$ production using a water target on a $13 \mathrm{MeV}$ cyclotron. Nucl. Med. Biol. 2014, 41, 401-406. [CrossRef] [PubMed]

25. Hoehr, C.; Bénard, F.; Buckley, K.; Crawford, J.; Gottberg, A.; Hanemaayer, V.; Kunza, P.; Ladouceur, K.; Radchenko, V.; Ramogida, C.; et al. Medical isotope production at TRIUMF-From imaging toTreatment. Phys. Procedia 2017, 90, 200-208. [CrossRef]

26. Hoehr, C.; Morley, T.; Buckley, K.; Trinczek, M.; Hanemaayer, V.; Schaffer, P.; Ruth, T.; Benard, F. Radiometals from liquid targets: ${ }^{94 \mathrm{~m}} \mathrm{Tc}$ production using a standard water target on a $13 \mathrm{MeV}$ cyclotron. Appl. Radiat. Isot. 2012, 70, 2308-2312. [CrossRef] [PubMed]

27. Pandey, M.K.; Byrne, J.P.; Jiang, H.; Packard, A.B.; Degrado, T.R. Cyclotron production of ${ }^{68}$ Ga via the ${ }^{68} \mathrm{Zn}(\mathrm{p}, \mathrm{n}){ }^{68} \mathrm{Ga}$ reaction in aqueous solution. Am. J. Nucl. Med. Mol. Imaging 2014, 4, 303-310. [PubMed]

28. Alves, F.; Alves, V.H.P.; Do Carmo, S.J.C.; Neves, A.C.B.; Silva, M.; Abrunhosa, A.J. Production of copper-64 and gallium-68 with a medical cyclotron using liquid targets. Mod. Phys. Lett. A 2017, 32, 21. [CrossRef]

29. Alves, V.H.; do Carmo, S.J.C.; Alves, F.; Abrunhosa, A.J. Automated Purification of Radiometals Produced by Liquid Targets. Instruments 2018, 2, 17. [CrossRef]

30. Riga, S.; Cicoria, G.; Pancaldi, D.; Zagni, F.; Vichi, S.; Dassenno, M.; Mora, L.; Lodi, F.; Morigi, M.P.; Marengo, M. Production of Ga-68 with a General Electric PETtrace cyclotron by liquid Target. Phys. Medica 2018, 55, 116-126. [CrossRef] [PubMed]

31. Esposito, J.; Vecchi, G.; Pupillo, G.; Taibi, A.; Uccelli, L.; Boschi, A.; Gambaccini, M. Evaluation of ${ }^{99}$ Mo and ${ }^{99 \mathrm{~m}} \mathrm{Tc}$ productions based on a high-performance cyclotron. Sci. Technol. Nucl. Ins. 2013, 2013, 972381. [CrossRef]

32. Qaim, S.M. Nuclear data for production and medical application of radionuclides: Present status and future needs. Nucl. Med. Biol. 2017, 44, 31-49. [CrossRef] [PubMed]

33. Mikolajczak, R.; Pawlak, D.; Wojdowska, W.; Janiak, T.; Barcikowski, T.; Zoltowska, M.; Cieszykowska, I.; Parus, J.; Hajdu, I.; Baranyai, G.; et al. Cyclotron production of Sc-44 from natural calcium. J. Nucl. Med. 2018, 59 (Suppl. 1), 1043.

34. Krajewski, S.; Cydzik, I.; Abbas, K.; Bulgheroni, A.; Simonelli, F.; Holzwarth, U.; Bilewicz, A. Cyclotron production of ${ }^{44} \mathrm{Sc}$ for clinical application. Radiochim. Acta 2013, 101, 333-338. [CrossRef]

35. Boschi, A.; Martini, P.; Janevik-Ivanovska, E.; Duatti, A. The emerging role of copper-64 radiopharmaceuticals as cancer theranostics. Drug Discov. Today 2018, 23, 1489-1501. [CrossRef] [PubMed]

36. Hosseini, S.F.; Aboudzadeh, M.; Sadeghi, M.; Teymourlouy, A.a.; Rostampour, M. Assessment and estimation of ${ }^{67} \mathrm{Cu}$ production yield via deuteron induced reactions on ${ }^{\text {nat }} \mathrm{Zn}$ and ${ }^{70} \mathrm{Zn}$. Appl. Radiat. Isot. 2017, 127, 137-141. [CrossRef] [PubMed]

37. Little, F.E.; Lagunas-Solar, M.C. Cyclotron production of ${ }^{67} \mathrm{Ga}$. Cross sections and thick-target yields for the ${ }^{67} \mathrm{Zn}(\mathrm{p}, \mathrm{n})$ and ${ }^{68} \mathrm{Zn}(\mathrm{p}, 2 \mathrm{n})$ reactions. Int. J. Appl. Radiat. Isot. 1983, 34, 631-637. [CrossRef]

38. Sadeghi, M.; Kakavand, T.; Rajabifar, S.; Mokhtari, M.; Rahimi-Nezhad, A. Cyclotron production of ${ }^{68}$ Ga via proton-induced reaction on ${ }^{68} \mathrm{Zn}$ target. Nucleonika 2009, 54, 25-28.

39. IAEA. Production of Long Lived Parent Radionuclides for Generators: ${ }^{68} \mathrm{Ge},{ }^{82} \mathrm{Sr},{ }^{90} \mathrm{Sr}$ and ${ }^{188} \mathrm{~W}$, IAEA Radioisotopes and Radiopharmaceuticals Series No. 2; International Atomic Energy Agency: Vienna, Austria, 2010; ISBN 978-92-0-101110-7.

40. Sadeghi, M.; Aboudzadeh, M.; Zali, A.; Zeinali, B. ${ }^{86} \mathrm{Y}$ production via ${ }^{86} \mathrm{Sr}(\mathrm{p}, \mathrm{n})$ for PET imaging at a cyclotron M. Appl. Radiat. Isot. 2009, 67, 1392-1396. [CrossRef] [PubMed] 
41. Kasbollah, A.; Eu, P.; Cowell, S.; Deb, P. Review on Production of ${ }^{89} \mathrm{Zr}$ in a Medical Cyclotron for PET Radiopharmaceuticals. Nucl. Med. Technol. 2013, 41, 35-41. [CrossRef] [PubMed]

42. Uzunov, N.M.; Melendez-Alafort, L.; Bello, M.; Cicoria, G.; Zagni, F.; De Nardo, L.; Selva, A.; Mou, L.; Rossi-Alvarez, C.; Pupillo, G.; et al. Radioisotopic purity and imaging properties of cyclotron-produced ${ }^{99 \mathrm{~m}}$ Tc using direct ${ }^{100} \mathrm{Mo}(\mathrm{p}, 2 \mathrm{n})$ reaction. Phys. Med. Biol. 2018, 63, 185021. [CrossRef] [PubMed]

43. Schaffer, P.; Benard, F.; Bernstein, A.; Buckleya, K.; Cellerc, A.; Cockburne, N.; Corsaute, J.; Dodda, M.; Economouf, E.; Eriksson, T.; et al. Direct Production of Tc-99m via Mo-100(p,2n) on Small Medical Cyclotrons. Phys. Procedia 2015, 66, 383-395. [CrossRef]

44. Chunfu, Z.; Yongxian, W.; Yongping, Z.; Xiuli, Z. Cyclotron production of no-carrier-added palladium-103 by bombardment of rhodium-103 target. Appl. Radiat. Isot. 2001, 55, 441-445. [CrossRef]

45. IAEA. TECDOC-1512, Production techniques and quality control of sealed radioactive sources of palladium-103, iodine-125, iridium-192 and ytterbium-169; International Atomic Energy Agency: Vienna, Austria, 2006; ISBN 92-0-108606-7.

46. Moustapha, M.E.; Ehrhardt, G.J.; Smith, C.J.; Szajek, L.P.; Eckelman, W.C.; Jurisson, S.S. Preparation of cyclotron-produced ${ }^{186} \mathrm{Re}$ and comparison with reactor-produced ${ }^{186} \mathrm{Re}$ and generator-produced ${ }^{188} \mathrm{Re}$ for the labeling of bombesin. Nucl. Med. Biol. 2006, 33, 81-89. [CrossRef]

47. Chou, W.; Chao, A.W. Reviews Of Accelerator Science And Technology-Volume 4. In Accelerator Applications in Industry and The Environment, 1st ed.; World Scientific Publishing Co Pte Ltd.: Singapore, 2012; ISBN-10 9789814383981.

48. Uccelli, L.; Pasquali, M.; Boschi, A.; Giganti, M.; Duatti, A. Automated preparation of Re-188 lipiodol for the treatment of hepatocellular carcinoma. Nucl. Med. Biol. 2011, 38, 207-213. [CrossRef]

49. Boschi, S.; Lodi, F.; Malizia, C.; Cicoria, G.; Marengo, M. Automation synthesis modules review. Appl. Radiat. Isot. 2012. [CrossRef] [PubMed]

50. Zaitseva, N.G.; Dmitriev, S.N. Radiochemical separation methods for preparation of biomedical cyclotron radionuclides. Czech. J. Phys. 1999, 49, 825-829. [CrossRef]

51. IAEA. Cyclotron produced radionuclides: Principles and Practice; IAEA Technical Reports Series No. 465; IAEA: Vienna, Austria, 2008.

52. Uccelli, L.; Boschi, A.; Cittanti, C.; Martini, P.; Lodi, L.; Zappaterra, E.; Romani, S.; Zaccaria, S.; Cecconi, D.; Rambaldi, I.; et al. Automated Synthesis of ${ }^{68} \mathrm{Ga}$-DOTA-TOC with a Cationic Purification System: Evaluation of Methodological and Technical Aspects in Routine Preparations. Curr. Radiopharm. 2018, 11, 130-137. [CrossRef] [PubMed]

53. Medvedev, D.G.; Mausner, L.F.; Meinken, G.E.; Kurczak, S.O.; Schnakenberg, H.; Dodge, C.J.; Korach, E.M.; Srivastava, S.C. Development of a large scale production of ${ }^{67} \mathrm{Cu}$ from ${ }^{68} \mathrm{Zn}$ at the high energy proton accelerator: Closing the ${ }^{68} \mathrm{Zn}$ cycle. Appl. Radiat. Isot. 2012, 70, 423-429. [CrossRef] [PubMed]

54. Martini, P.; Boschi, A.; Cicoria, G.; Uccelli, L.; Pasquali, M.; Duatti, A.; Pupillo, G.; Marengo, M.; Loriggiola, M.; Esposito, J. A solvent-extraction module for cyclotron production of high-purity technetium-99m. Appl. Radiat. Isot. 2016, 118, 302-307. [CrossRef] [PubMed]

55. Boschi, A.; Martini, P.; Pasquali, M.; Uccelli, L. Recent achievements in Tc-99m radiopharmaceutical direct production by medical cyclotrons. Drug Dev. Ind. Pharm. 2017, 43, 1402-1412. [CrossRef]

56. Chattopadhyay, S.; Das, S.S.; Barua, L. A simple and rapid technique for recovery of ${ }^{99 \mathrm{~m}} \mathrm{Tc}$ from $10 \mathrm{w}$ specificactivity ${ }^{98} \mathrm{Mo}(\mathrm{n}, \gamma){ }^{99} \mathrm{Mo}$ based on solvent extraction and column chromatography. Appl. Radiat. Isot. 2010, 68. [CrossRef]

57. Chattopadhyay, S.; Barua, L.; De, A.; Das Saha, S.; Kuniyil, R.; Bhaskar, P.; Pal Shekhar, S.; Sarkar, S.K.; Das Kanti, M. A computerized compact module for separation of ${ }^{99 \mathrm{~m}}$ Tc-radionuclide from molybdenum. Appl. Radiat. Isot. 2012, 70, 2631. [CrossRef]

58. Capogni, M.; Pietropaolo, A.; Quintieri, L.; Angelone, M.; Boschi, A.; Capone, M.; Cherubini, N.; De Felice, P.; Dodaro, A.; Duatti, A. $14 \mathrm{MeV}$ Neutrons for ${ }^{99} \mathrm{Mo} /{ }^{99 \mathrm{~m}} \mathrm{Tc}$ Production: Experiments, Simulations and Perspectives. Molecules 2018, 23, 1872. [CrossRef]

59. Uccelli, L.; Boschi, A.; Martini, P.; Cittanti, C.; Bertelli, S.; Bortolotti, D.; Govoni, E.; Lodi, L.; Romani, S.; Zaccaria, S.; et al. Influence of Storage Temperature on Radiochemical Purity of ${ }^{99 \mathrm{~m}}$ Tc-Radiopharmaceuticals. Molecules 2018, 23, 661. [CrossRef]

60. Uccelli, L.; Martini, P.; Pasquali, M.; Boschi, A. Radiochemical purity and stability of $99 \mathrm{~m}$ Tc-HMPAO in routine preparations. J. Radioanal. Nucl. Chem. 2017, 314, 1177-1181. [CrossRef] 
61. Asti, M.; De Pietri, G.; Fraternali, A.; Grassi, E.; Sghedoni, R.; Fioroni, F.; Roesch, F.; Versari, A.; Salvo, D. Validation of ${ }^{68} \mathrm{Ge} /{ }^{68} \mathrm{Ga}$ generator processing by chemical purification for routine clinical application of ${ }^{68}$ Ga-DOTATOC. Nucl. Med. Biol. 2008, 5, 721-725. [CrossRef] [PubMed]

62. Aerts, J.; Ballinger, J.R.; Behe, M.; Decristoforo, C.; Elsinga, f.P.H.; Faivre-Chauvet, g.A.; Mindt, T.L.; Kolenc Peitl, P.; Todde, S.C.; Koziorowskik, J. Guidance on current good radiopharmacy practice for the small-scale preparation of radiopharmaceuticals using automated modules: A European perspective. Protocols Methods J. Label Compd. Radiopharm. 2014, 57, 615-620. [CrossRef] [PubMed]

63. Gagnon, K.; Wilson, J.S.; Holt, C.M.; Abrams, D.N.; McEwan, A.J.; Mitlin, D.; McQuarrie, S.A. Cyclotron production of Tc-99m: Recycling of enriched Mo-100 metal targets. Appl. Radiat. Isot. 2012, 70, 1685-1690. [CrossRef] [PubMed]

64. Matarrese, M.; Bedeschi, P.; Scardaoni, R.; Sudati, F.; Savi, A.; Pepe, A.; Masiello, V.; Todde, S.; Gianolli, L.; Messa, C.; et al. Automated production of copper radioisotopes and preparation of high specific activity [(64)Cu]Cu-ATSM for PET studies. Appl. Radiat. Isot. 2010, 68, 5-13. [CrossRef] [PubMed]

65. Mausner, L.F.; Srivastava, S.C. Selection of radionuclides for radioimmunotherapy. Med. Phys. 1993, 20, 503-509. [CrossRef] [PubMed]

66. Kolsky, K.L.; Joshi, V.; Mausner, L.F.; Srivastava, S.C. Radiochemical purification of no-carrier-added scandium-47 for radioimmunotherapy. Appl. Radiat. Isot. 1998, 49, 1541-1549. [CrossRef]

67. Minegishi, K.; Nagatsu, K.; Fukada, M.; Suzuki, H.; Ohya, T.; Zhang, M.-R. Production of scandium-43 and-47 from a powdery calcium oxide target via the ${ }^{\text {nat } / 44} \mathrm{Ca}(\alpha, \mathrm{x})$-channel. Appl. Radiat. Isotop. 2016, 116, 8-12. [CrossRef]

68. Khandaker, M.U.; Kim, K.; Lee, M.W.; Kim, K.S.; Kim, G.N.; Cho, Y.S.; Lee, Y.O. Investigations of the ${ }^{\text {nat }} \mathrm{Ti}(\mathrm{p}, \mathrm{x})^{43,44 \mathrm{~m}, 44 \mathrm{~g}, 46,47,48} \mathrm{Sc}^{48} \mathrm{~V}$ nuclear processes up to $40 \mathrm{MeV}$. Appl. Radiat. Isot. 2009, 67, 1348-1354. [CrossRef]

69. Pietrelli, L.; Mausner, L.F.; Kolsky, K.L. Separation of carrier free ${ }^{47}$ Sc from titanium targets. J. Radioanal. Nucl. Chem. 1992, 157, 335-345. [CrossRef]

70. Domnanich, K.A.; Eichler, R.; Müller, C.; Jordi, S.; Yakusheva, V.; Braccini, S.; Behe, M.; Schibli, R.; Türler, A.; van der Meulen, N.P. Production and separation of ${ }^{43} \mathrm{Sc}$ for radiopharmaceutical purposes. EJNMMI Radiopharm. Chem. 2017, 2, 14. [CrossRef]

71. Barto’s, B.; Majkowska, A.; Kasperek, A.; Krajewski, S.; Bilewicz, A. New separation method of no-carrier-added ${ }^{47}$ Sc from titanium Targets. Radiochim. Acta 2012, 100, 457-461. [CrossRef]

72. Pourmand, A.; Dauphas, N. Distribution coefficients of 60 elements on TODGA resin: Application to ca, Lu, Hf, U and Th isotope geochemistry. Talanta 2010, 81, 741-753. [CrossRef] [PubMed]

73. Esposito, J.; Bettoni, D.; Boschi, A.; Calderolla, M.; Cisternino, S.; Fiorentini, G.; Keppel, G.; Martini, P.; Maggiore, M.; Mou, L.; et al. LARAMED: A Laboratory for Radioisotopes of Medical Interest. Molecules 2019, 24, 20. [CrossRef] [PubMed]

74. Van der Meulen, N.P.; Bunka, M.; Domnanich, K.A.; Müller, C.; Haller, S.; Vermeulen, C.; Türler, A.; Schibli, R. Cyclotron production of ${ }^{44}$ Sc: From bench to bedside. Nucl. Med. Biol. 2015, 42, 745-751. [CrossRef] [PubMed]

(c) 2019 by the authors. Licensee MDPI, Basel, Switzerland. This article is an open access article distributed under the terms and conditions of the Creative Commons Attribution (CC BY) license (http://creativecommons.org/licenses/by/4.0/). 